forecasting model is based on multiple regressions and involves following variables: discharge, air temperature, global radiation, precipitation and the altitude of the snow-cover limit. The selection of the variables not only depends on the physical laws of the melting of glaciers but also on the possibilities of measuring them accurately. The melt-water run-off is not a stationary process, but this difficulty can be by-passed by introducing the altitude of the snowcover limit and by subdividing the melt season into intervals. The model must automatically choose the equations corresponding to the actual interval. The quality of the forecasts essentially depends on the weather forecast; some difficulties, such as the precipitation in the forecasted period, have not yet been resolved. The utilization of discharge forecasts in an optimizing model for the operation of a pumping plant with a compensation basin is compulsory and, further, enables the maximum usage of low-price electrical energy, limits water losses, and guarantees operational security.

\title{
IGE AVALANGHES
}

\section{By Hans RöThlisberger}

(Versuchsanstalt für Wasserbau, Hydrologie und Glaziologie, Eidgenössischen Technischen Hochschule Zürich, CH-8o44 Zürich, Switzerland)

Abstract. Our knowledge of ice avalanches is very limited in comparison to snow avalanches, for obvious reasons. Ice avalanches are restricted to remote areas with glaciers, whereas snow avalanches may occur in the middle of inhabited regions. Consequently, the economic importance of the two types of avalanches is quite different. Also the efforts and expenditure required to study them are different.

Two classes of ice avalanches may be discerned (with no sharp dividing line between them). A common form occurs on steep glacierized slopes below ice cliffs, from which ice breaks off at intervals. The avalanche debris remains on the glacier and can either be reincorporated or can form a regenerated glacier tongue. This is the type of ice avalanche primarily noticed by mountaineers because of the hazards involves, although little seems to have been done in the way of glaciological studies. A second class of ice avalanches consists of events more akin to landslides where a considerable portion of a glacier falls off a steep part of the bed and moves beyond the original position of the glacier onto ice-free ground, sometimes with disastrous effects. Through such glacier catastrophes, which are fortunately very scarce, more intensive glaciological studies have been initiated. The individual case histories serve best to illustrate the various problems related to ice avalanches.

The Altels avalanche of I I September I 895, thoroughly documented by Heim (1896), can be regarded as a slab of ice sliding off a uniform inclined plane. It is remarkable for its size of $4.5 \times 10^{6} \mathrm{~m}^{3}$, its simple geometry at the origin, its equally simple trajectory involving a jump through the air, and the fact that in 1782 a similar avalanche had occurred. The slope of the bed at the origin was $30^{\circ}$ to $32^{\circ}$, the mean ice thickness was $25 \mathrm{~m}$ (with a maximum of $40 \mathrm{~m})$. No apparent signs had been noticed in the days preceding the catastrophe. The Altels avalanche provides one of the few sources of reliable empirical parameters in relation to ice stability and ice-avalanche dynamics.

The Allalingletscher avalanche of 30 August ${ }_{196} 6_{5}$ hitting the Mattmark construction site was of a very different origin. It occurred when about $10^{6} \mathrm{~m}^{3}$ of ice broke off at the snout of the glacier during a surge-like active phase of a larger mass of some $3 \times 10^{6} \mathrm{~m}^{3}$. Since this event, it has been established that such active phases occur periodically at Allalin once every I-3 years, alternating with quiescent periods. During the active phase, the fast motion sometimes starts in summer or autumn and comes to a halt in November or December. The 
active phase seems to depend on the presence of melt water and also on mass distribution. A direct effect of high water pressure in a communicating drainage system at the bed can be excluded, however. The surge-like motion appears to have been a prerequisite for the ice avalanche of 1965 , but it does not give a sufficient explanation of the event, when one considers the frequent occurrence of active phases without a concurrent major ice avalanche at Allalin and elsewhere. It is conceivable that in 1965 a large dome-shaped cavity had formed below a particular rock knob and that the collapse of the dome then triggered the avalanche, but other forms of static instability at high speed of bed slip, developing because of a specific bed morphology and mass distribution, may equally be envisaged.

In the case of a hanging glacier on the Weisshorn, the village of Randa was severely damaged in 1819 by a very large avalanche approximately $13 \times 10^{6} \mathrm{~m}^{3}$ consisting mainly of snow but having been triggered by falling ice. This led to a detailed study in r $972 / 73$ of a seemingly threatening situation. A volume of approximately $5 \times 10^{6} \mathrm{~m}^{3}$ of ice (firn) was accelerating in a characteristic way on a very steep slope of about $45^{\circ}$. Rough estimates showed that the acceleration was too large to be accounted for by frictional heating alone; a fracture mechanism had instead to be invoked to play the decisive role (besides possible recrystallization). A hyperbolic law has been found to fit best the data on change of velocity with time (Flotron, see the following abstract).

The Huascaran catastrophes of 1962 and 1970 have been some of the most disastrous events in glaciological history. In 1962 a true ice avalanche appears to have been the cause of a giant mudflow (Morales, r 966 ). For the first time in at least several hundred years a large volume, estimated at 2.5 to $3 \times 10^{6} \mathrm{~m}^{3}$, broke off simultaneously over the full length of an ice cliff, $800 \mathrm{~m}$ long and 50 to $60 \mathrm{~m}$ high. It is an open question as to how this could happen. The mudflow was formed by mixing of the ice with rock and soil picked up along the course of the avalanche, bringing the total volume ot some $13 \times 10^{6} \mathrm{~m}^{3}$. In this process part of the ice was melted. The 1970 incident was not an ice avalanche proper, but rather a giant landslide caused by an earthquake, in which the ice played an important role in the form of a source of water causing lubrication and liquefaction.

The above examples constitute a diversity of problems which could be augmented further by additional cases. A certain order may nevertheless be brought to the subject of ice avalanches by looking at it from a practical point of view. The main objective is to look for means by which damage to property can be reduced and loss of life avoided.

The basic question is the one of stability of a large ice mass on a steep slope. The problem seems to be simple enough, but a closer inspection shows that the time scale and the unknown factors are such that laboratory results of, for example, strength are of no avail. On an empirical basis it can be noticed that temperate glaciers have become unstable on a slope of about $30^{\circ}$, while the limiting slope of cold glaciers is about $45^{\circ}$. The distribution and development of crevasses and, more generally, the flow pattern can help to delineate an acutely unstable ice mass. A special condition is the occurrence of a surge-like active phase which should be taken as an indication that part of the fast moving ice may slide off. There is a basic rule applicable to all types of ice avalanches, that if a particular one has occurred once it will happen again in a similar way; unfortunately our records do not extend sufficiently far back to allow us to depend on this rule very often.

The probable extent of the danger zone is of equal practical importance. Experience has shown that after an initial phase the ice becomes completely broken up so that snow-avalanche dynamics can be applied to estimate how far the debris will move, possibly with some modifications for large masses of landslide dimensions. The possibility that snow and loose rock and soil may be added along the path must be taken into account. Secondary effects must also be considered. Amongst these are an air blast, or the formation of destructive water waves in a lake or fjord, or the blockage of a river by a huge ice mass leading to a flood from an icedammed lake. 
A warning by the glaciologist is hardly taken seriously unless it includes a forecast of the time of final rupture. At present the most promising approach for such a prediction is the almost perfect regularity by which certain large ice masses accelerate for a very long time prior to the instant when the avalanche starts to fall (see the Weisshorn case). The limitation of the forecasts lies as much in short-term irregularities as in the extreme difficulties of obtaining sufficiently accurate data without interruptions, and further in the lack of experience on the critical velocity that is reached immediately before final breakage. The physical explanation of the observed law is another question. Using a finite-element computational model for the analysis of stress and flow in a somewhat different case, Iken (1977) has shown that a stepwise crack extension alternating with phases of flow leads to the observed form of velocity-time relationship.

There are various possibilities in the way of preventive measures; none of them is completely satisfactory, however. The most certain consists in avoiding the danger zone altogether, a solution usually not acceptable to those involved. In view of the requirements necessary for withstanding an impact of exceptional magnitude, protective structures are generally not practical either. A stepwise elimination of the unstable ice mass by blasting could be considered, though the realization would be difficult and not without danger - not to speak of the legal problem encountered if the blasting should trigger the full-size avalanche. Consequently a certain calculated risk will occasionally have to be accepted whereby the dangers during an operation on the glacier and the extreme costs have to be weighed against the severity and small probability of a catastrophe. Viewed in proportion to other risks in everyday life (especially in road and air traffic, but also in relation to earthquakes), the dangers of ice avalanches should not be exaggerated.

Glaciological research can obviously contribute in a variety of ways to the solution of practical problems with ice avalanches, and there are ample opportunities for future studies. Of urgent need are more and better observations on almost every aspect of the problem, extending to phenomena hitherto not observed such as frequency and intensity of seismic signals. The inherent difficulty with the more interesting large-scale events is their scarcity, precluding proper experimentation. Advances in the theoretical treatment are also to be hoped for. There is also room for new ideas, for instance on how to prevent a particular ice mass from forming.

\title{
REFERENCES
}

Heim, A. 1896. Die Gletscherlawine an der Altels am I I. September I 895. $98^{\text {stes }}$ Neujahrsblatt der Naturforschenden Gesellschaft in Zürich, $1895,63 \mathrm{p}$.

Iken, A. I977. Movement of a large ice mass before breaking off. Journal of Glaciology, Vol. I 9, No. 8I, p. 595-6o5.

Morales, B. 1966. The Huascarán avalanche in the Santa valley, Peru. Union de Géodésie et Géophysique Internationale. Association Internationale d'Hydrologie Scientifique. Commission pour la Neige et la Glace. Division Neige Saisonnière et Avalanches. Symposium international sur les aspects scientifiques des avalanches de neige, 5-10 avril 1965, Davos, Suisse, p. 304-15. (Publication No. 69 de l'Association Internationale d'Hydrologie Scientifique.)

\section{MOVEMENT STUDIES ON A HANGING GLACIER IN RELATION WITH AN ICE AVALANGHE}

\author{
By ANDré FLotron \\ (Vermessungsbüro, Meiringen, Switzerland)
}

Abstract. In 1972 the state of a hanging glacier on the Weisshorn gave cause for alarm, as part of it seemed to be accelerating and a repetition of an earlier avalanche of ice seemed possible (see Röthlisberger, previous abstract). For this reason movement surveys were undertaken. The various surveying methods applied on the Weisshorn are outlined and the 